\title{
Taxonomic Distinctness of the Intertidal Fish Community on the Pacific Coast of Baja California Sur, México
}

\author{
Emelio Barjau-González ${ }^{*}{ }^{\circledR}$, José Ange Armenta-Quintana² ${ }^{\circledR}$, Juan Manuel López-Vivas ${ }^{1}{ }^{\circledR}$, \\ Eleonora Romero-Vadillo ${ }^{1}$
}

\author{
${ }^{1}$ Departamento Académico de Ciencias Marinas y Costeras, Universidad Autónoma de Baja California Sur, La Paz, México \\ ${ }^{2}$ Departamento Académico de Ciencia Animal y Conservación del Hábitat, Universidad Autónoma de Baja California Sur, La Paz, México \\ Email: ^ebarjau@uabcs.mx, jarmenta@uabcs.mx, jmlopez@uabcs.mx, eromero@uabcs.mx
}

How to cite this paper: Barjau-González, E., Armenta-Quintana, J.A., López-Vivas, J.M. and Romero-Vadillo, E. (2019) Taxonomic Distinctness of the Intertidal Fish Community on the Pacific Coast of Baja California Sur, México. Open Journal of Marine Science, 9, 86-97.

https://doi.org/10.4236/ojms.2019.92007

Received: February 11, 2019

Accepted: April 9, 2019

Published: April 12, 2019

Copyright $\odot 2019$ by author(s) and Scientific Research Publishing Inc. This work is licensed under the Creative Commons Attribution International License (CC BY 4.0).

http://creativecommons.org/licenses/by/4.0/

\begin{abstract}
The intertidal zone is a complex coastal area exposed to a wide variety of environmental factors. During low tide, rocky pools are exposed to air for several hours throughout the day, and environmental conditions such as temperature and salinity are highly variable. Fish communities that inhabit these tide pools are also exposed to environmental variability; therefore it is important to look at fish community structure in relation to important environmental factors such as temperature, salinity and dissolved oxygen on tide pools during spring tides, time of greater exposure to air. Therefore, the aim of the present study was to analyze the variation of the taxonomic distinctness of intertidal fish communities considering temperature, salinity and dissolved oxygen of the water that remains trapped in the tide pools during low tide. Visual census surveys were carried out monthly, from January to December 2015, in the intertidal zone of El Faro during spring tides on full moon days, when fluctuations of environmental variables are significant. Total extension of the census surveys was $156 \times 5 \mathrm{~m}\left(780 \mathrm{~m}^{2}\right)$. A total of 145 tide pools were sampled and divided in three groups (small, medium and large) according to size and depths that ranged from 20 to $45 \mathrm{~cm}$. Temperature, salinity and dissolved oxygen fluctuate throughout the year of study. Thermal difference between open ocean and tide pools ranged from $3.5^{\circ} \mathrm{C}$ to $4.5^{\circ} \mathrm{C}$. A total of 3757 organisms from 22 species, 12 families, four orders and one class were recorded. When comparing taxonomic distinctness and average taxonomic distinctness between months and tide pools of different sizes, values fell within the confidence intervals in the tunnel and were located close to the mean.
\end{abstract}

\section{Keywords}

Taxonomic Distinctness, Exposed Coast, Climate Change 


\section{Introduction}

The intertidal zone is an area of transition between low and high tide, and it is characterized by key ecosystems such as sandy and rocky beaches. There are many fish species inhabiting the intertidal zone and use the complex rocky areas as shelter to survive and withstand environmental change. During low tide, physicochemical variables such as temperature, salinity and dissolved oxygen can be highly variable during the day, particularly in exposed habitats such as tide pools, as a result from air exposure and solar incidence. Intertidal zones are also a source of important ecosystem services; therefore, anthropogenic impacts may increase vulnerability of these ecosystems to climate change, particularly global warming. Geomorphology of coastal areas regulates their structure and ecological dynamic, and is a useful reference to interpret environmental impacts, with special attention on those intensified by climate change [1] [2]. There are not many studies of fish communities inhabiting the intertidal zone in México that include long term collection of critical environmental parameters and their influence on the taxonomic distinctness. According to a previous work carried out in El Salvador [3], studies on fish communities of intertidal zones in tropical regions (including México) are limited, making this an important contribution to increase the knowledge on intertidal zones on the west coast of Baja California, México [4] [5]. Regarding studies on taxonomic diversity, previous studies analyzed structure of the communities, and there are no previous studies about taxonomic distinctness of the intertidal fish communities in this region, making the present study a great contribution to better understand the dynamics of intertidal fish communities of this region. Therefore, the aim of the present study was to determine the taxonomic distinctness of fish communities trapped in tide pools during low tide and its relation with physicochemical variables such as temperature, salinity and dissolved oxygen.

\section{Methods}

\section{Studyarea}

The site known as "El Faro" is located $24 \mathrm{~km}$ west of the common land known as Conquista Agraria, at N23 57.351 and W110 52.437. The study area is located 524m north from El Faro, between N23 57.553 and W110 52.654 to N23 57.622 and W110 52.705 (Figure 1).

\section{Fieldwork}

Monthly samplings were carried out in the intertidal zone during the full moon days, from January to December 2015. Fish were counted by visual census surveys using transects of $156 \times 5 \mathrm{~m}$. 145 tide pools were recorded and divided in three groups (small: $2 \mathrm{~m}^{2}$, medium: $4 \mathrm{~m}^{2}$ and large: $7 \mathrm{~m}^{2}$ ) according to size and depths that ranged from 20 to $40 \mathrm{~cm}$. In that area, tide pools are located 122 $\mathrm{cm}$ above sea level.

\section{Ecological indices}

To determine taxonomic diversity of this fish community the following ecological 


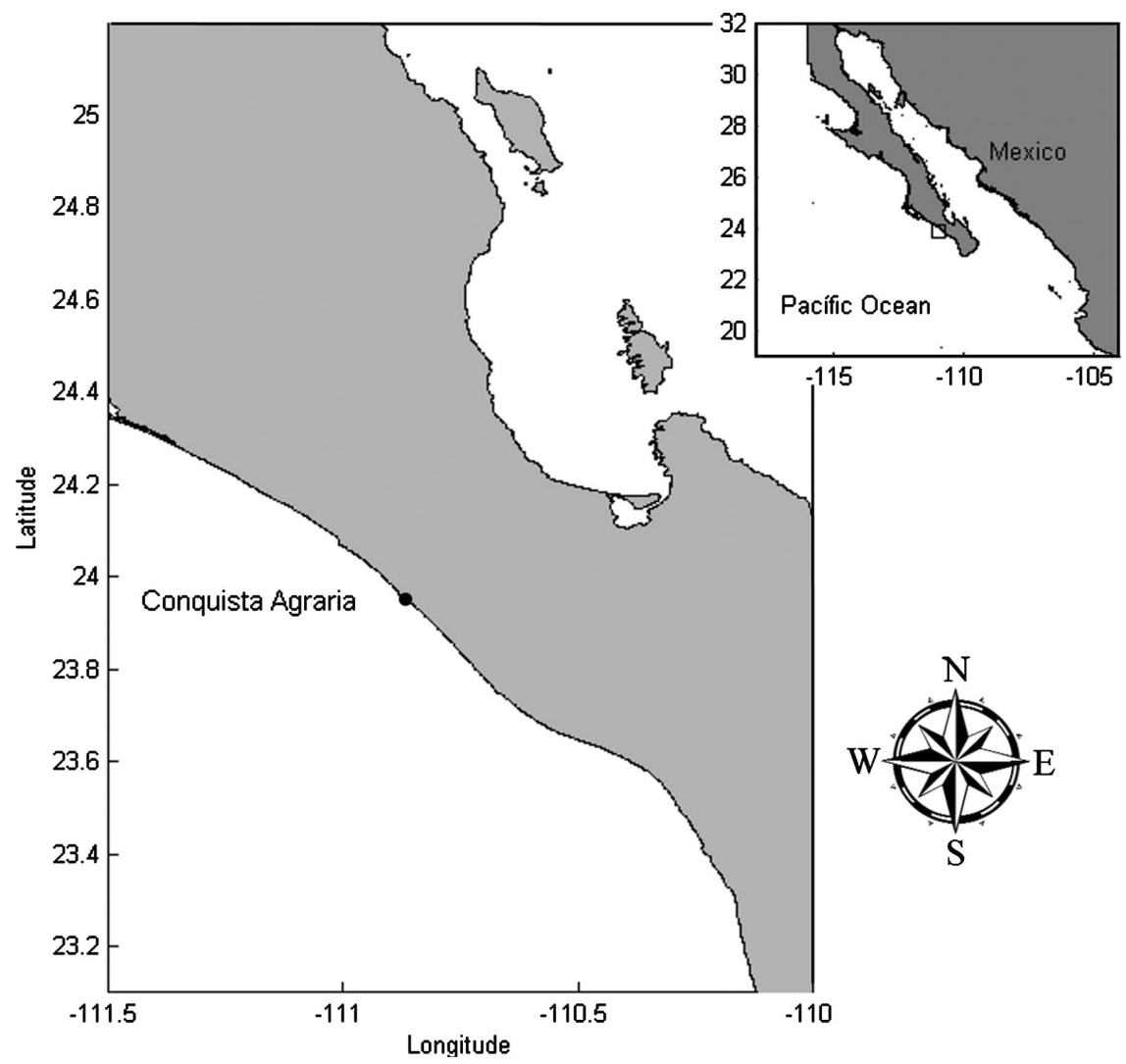

Figure 1. Geographic location of the sampling sites of fish species sampled in Conquista Agraria Baja California Sur, Pacific coast.

indices were used:

Species richness $(D)$ :

$$
D=(S-1) / \ln (N)
$$

where: $D=$ Species richness, $S=$ Number of species, $N=$ Number of individuals.

Fisher's alpha ( $\alpha$-Fisher):

$$
s=\alpha \ln (1+N / \alpha)
$$

where: $S=$ Number of species in the sample, $N=$ Number of individuals in the sample and $\alpha=$ Diversity coefficient.

Taxonomic distinctness index $\left(\mathrm{TD} \Delta^{\star}\right)[6]$.

$$
\Delta^{*}=\frac{\sum \sum_{i<j} w_{i j} x_{i} x_{j}}{\sum \sum_{i<j} x_{i} x_{j}}
$$

where: $x_{i}(i=1,2, \cdots, s)$ denotes the abundance of the $i$ th specie and $w_{i j}=$ weight difference resulting from the branch length between species in lines $i$ and $j$ in the hierarchical classification. This index evaluates taxonomic distance and species richness, using the total species abundance, and has been considered a more precise measure of biodiversity, since it incorporates qualitative as well as quantitative aspects of the fauna or flora.

Average taxonomic distinctness index $\left(\operatorname{AvTD} \Delta^{+}\right)[7]$ : 


$$
\Delta^{+}=2 \frac{\sum \sum_{i<j} w_{i j}}{S(s-1)}
$$

where: $\Delta^{+}=$average taxonomic distinctness, $S=$ species richness, and $w_{i j}=$ weight difference resulting from the branch length between species in lines $i$ and $j$ in the hierarchical classification.

This index evaluates richness as well as the taxonomic distance of each species pair, defined through a Linnean classification tree. In both of these last two indices each hierarchical taxonomic level gets a discrete and proportional value in a scale that goes from 0 to 100 . These indices are independent of sample size and do not need data normality. For the first index, we used the total abundance data, standardized according to [6]; for the second index [7], we used presence/absence data. To calculate these indices six hierarchical levels were used: species, genus, family, order, and class.

Physicochemical variables (temperature, salinity and dissolved oxygen) were recorded using a YSI 2030 Pro multiparameter instrument. Ecological indices were analyzed using the software Primer-E \& Permanova 6 and statistical analysis was performed using Statistica v.8. Species identifications were carried out using specialized literature [8] [9] [10] [11].

\section{Results}

\section{Physicochemical variables}

Water temperature in the tide pools showed great variation. Mean temperature was $28.18^{\circ} \mathrm{C}$, with significant differences between months $(\mathrm{F}(11,24)=$ $379.93, \mathrm{p}<0.001)$. September was the warmest month $\left(32.64^{\circ} \mathrm{C}\right)$, followed by August and October $\left(32.53^{\circ} \mathrm{C}\right.$ and $32.43^{\circ} \mathrm{C}$, respectively). The coldest month was January $\left(24.30^{\circ} \mathrm{C}\right)($ Table 1$)$. Comparing between tide pools of different size and depths, there were no significant differences of temperature $(F 2,33)=0.0283, p$ $=0.9721)$. The overall mean salinity was 30.31 UPS, with significant differences between months $(\mathrm{F}(11,24)=12.0361, \mathrm{p}<0.001)$. Highest salinity was recorded in September (32.3 UPS) and the lowest was recorded during April (27.56 UPS) (Table 1). Comparing between tide pools of different size and depths, there were no significant differences of salinity $(F(2,33)=0.0283, p=0.3331)$. Overall dissolved oxygen in the tide pools was $10.21 \mathrm{mg} / \mathrm{L}$ (Table 1 ). There were no significant differences between months $(\mathrm{F}(11,24)=0.9994, \mathrm{p}=0.4749)$ and when comparing between tide pools of different size and depths $(\mathrm{F}(2,33)=1.0009, \mathrm{p}$ $=0.3784$ ).

\section{Taxonomic diversity}

A total of 3757 organisms from 22 species, 12 families, four orders and one class were recorded and distributed in the tide pools as follows: 85 small tide pools (1914 organisms), 48 medium tide pools (1314 organisms) and 12 large tide pools (526 organisms). Species richness showed significant differences ( $F$ $(12,24)=10,606.9271, \mathrm{p}<0.001)$, with April and June recording the highest values (3.56 and 3.53, respectively), and December and February recording the 
lowest values (1.66 and 2.20, respectively) (Table 1). Fisher's alpha was also used because it includes rare species, giving them the same value regardless of their abundance and has higher biological significance. April and July recorded the highest values ( $S=7.164$ and $S=7.106$, respectively), and the lowest value was recorded in December $(S=2.89)$ (Table 1).

Taxonomix distinctness (TD $\Delta^{*}$ ) was determined per month and per tide pool. The highest value was recorded in April $\left(\Delta^{*}=186.8\right)$, while the lowest value was recorded in September $\left(\Delta^{*}=50.17\right)$ (Figure 2, Table 1). Comparison

Table 1. Physicochemical variables: temperature $\left(\mathrm{T}^{\circ} \mathrm{C}\right)$, salinity (UPS), dissolved oxygen (DO), and taxonomic diversity values: number of species (spp), abundance (Abun), species richness (d), Fisher's alpha diversity ( $\alpha$-Fisher), taxonomic distinctness (TD $\Delta^{\star}$ ) and average taxonomic distinctness $\left(\mathrm{TD} \Delta^{+}\right.$) recorded at tide pools of the intertidal zone at El Faro, Conquista Agraria, Baja California Sur, México.

\begin{tabular}{|c|c|c|c|c|c|c|c|c|c|c|}
\hline Months & Temperature & Salinity & DO & spp & Abun & d & $a$-Fisher & Simpson & $\operatorname{TD} \Delta^{*}$ & $\operatorname{ATD} \Delta^{+}$ \\
\hline January & 24.1 & 28.5 & 16.04 & 10 & 550 & 2.28 & 3.69 & 0.8104 & 177 & 60.89 \\
\hline February & 27.3 & 31.6 & 7.2 & 10 & 628 & 2.203 & 3.441 & 0.8366 & 177 & 60.89 \\
\hline March & 26.3 & 31.8 & 8.95 & 12 & 473 & 2.67 & 4.449 & 0.8897 & 151.4 & 60.3 \\
\hline April & 24.7 & 27.4 & 10.86 & 15 & 235 & 3.561 & 7.164 & 0.9278 & 186.8 & 61.9 \\
\hline May & 26.4 & 31.5 & 6.48 & 12 & 223 & 2.925 & 5.524 & 0.9002 & 145.1 & 60.61 \\
\hline June & 27 & 29 & 6.2 & 14 & 253 & 3.344 & 6.569 & 0.9124 & 142.6 & 63.96 \\
\hline July & 29.2 & 30.3 & 5.77 & 15 & 318 & 3.535 & 7.016 & 0.9018 & 113.7 & 60.76 \\
\hline August & 32.3 & 31.9 & 9.28 & 13 & 260 & 3.073 & 5.733 & 0.9128 & 133.1 & 60.51 \\
\hline September & 32.5 & 31.5 & 8.15 & 10 & 151 & 2.551 & 4.769 & 0.8961 & 50.17 & 58.22 \\
\hline November & 29.2 & 28 & 11.1 & 13 & 254 & 3.099 & 5.855 & 0.909 & 157.5 & 64.1 \\
\hline December & 25.2 & 31.9 & 25.2 & 6 & 84 & 1.664 & 2.887 & 0.8352 & 88.89 & 66.67 \\
\hline
\end{tabular}

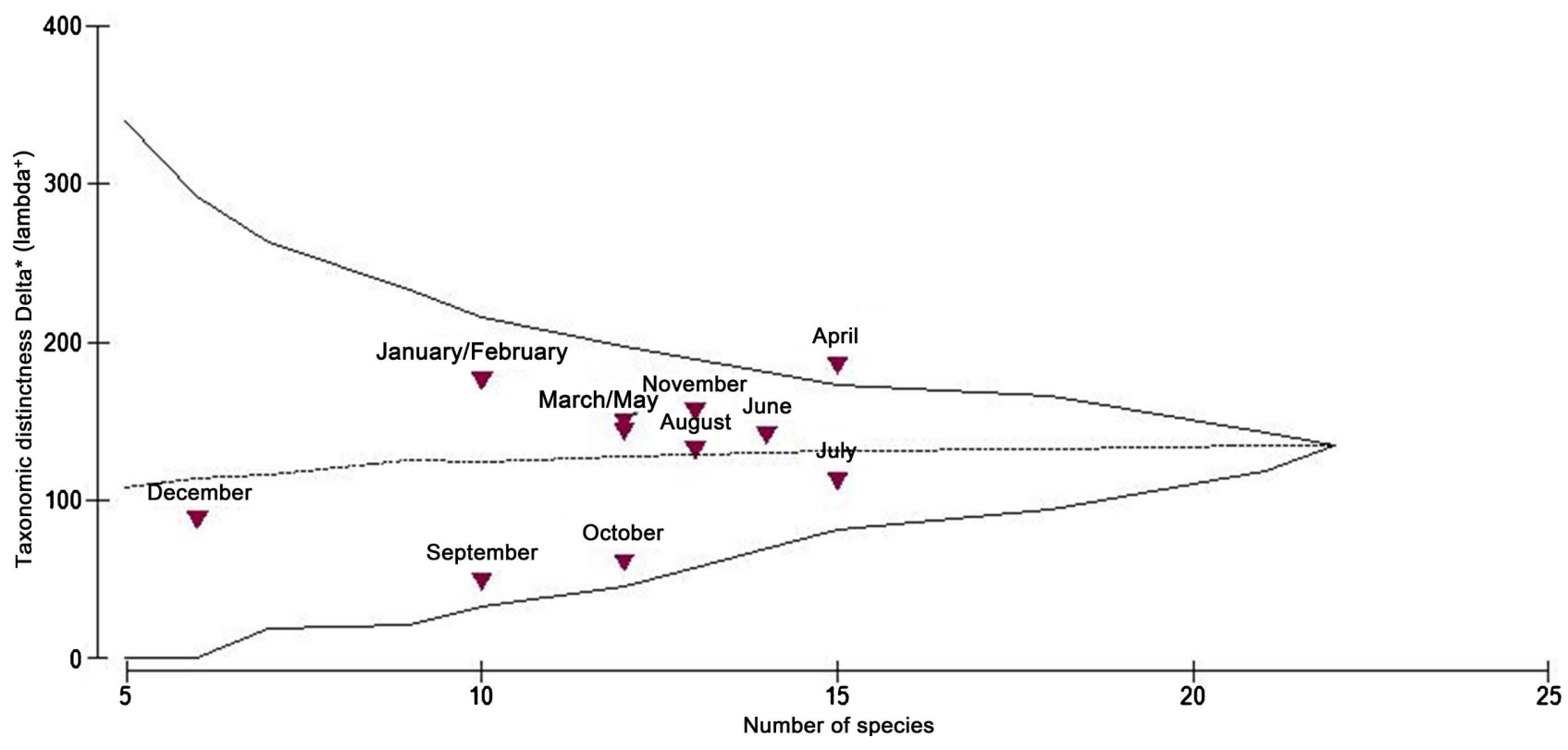

Figure 2. Taxonomic distinctness $\left(\mathrm{TD} \Delta^{\star}\right)$ at each month. 
between tide pools showed the majority of tide pools within the confidence intervals, and only three of them were located above them (Figure 3).

Average taxonomic distinctness $\left(\operatorname{AvTD} \Delta^{+}\right)$showed all months were within the confidence intervals, close to the mean line. December recorded the highest value $\left(\Delta^{+}=66.67\right)$, while the lowest value was recorded for October $\left(\Delta^{+}=57.88\right)$ (Figure 4, Table 1). Comparison between tide pools showed the majority of tide pools within the confidence intervals, similar to the comparison between months (Figure 5).

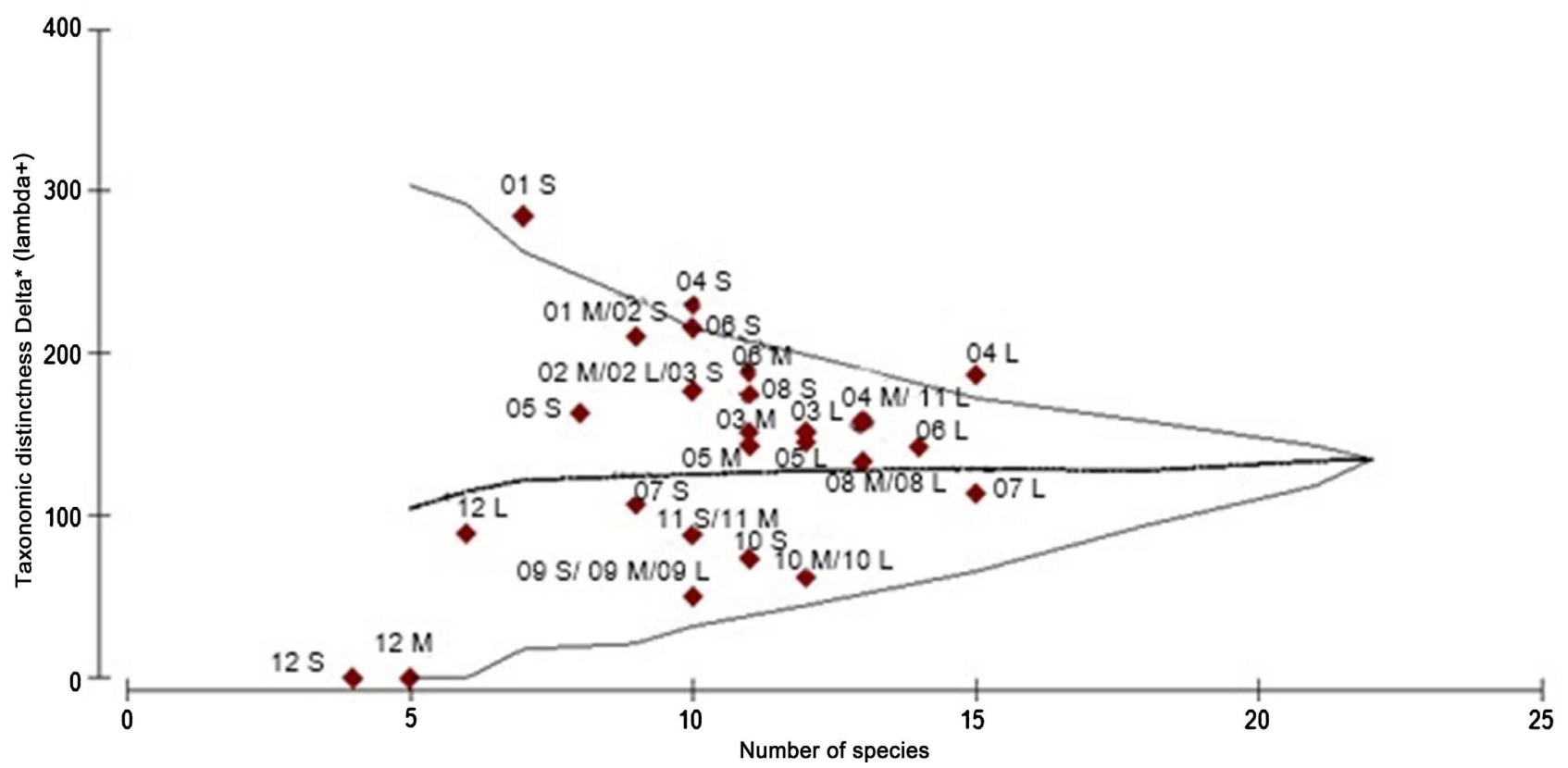

Figure 3. Taxonomic distinctness (TD $\Delta^{*}$ ) of tide pools.

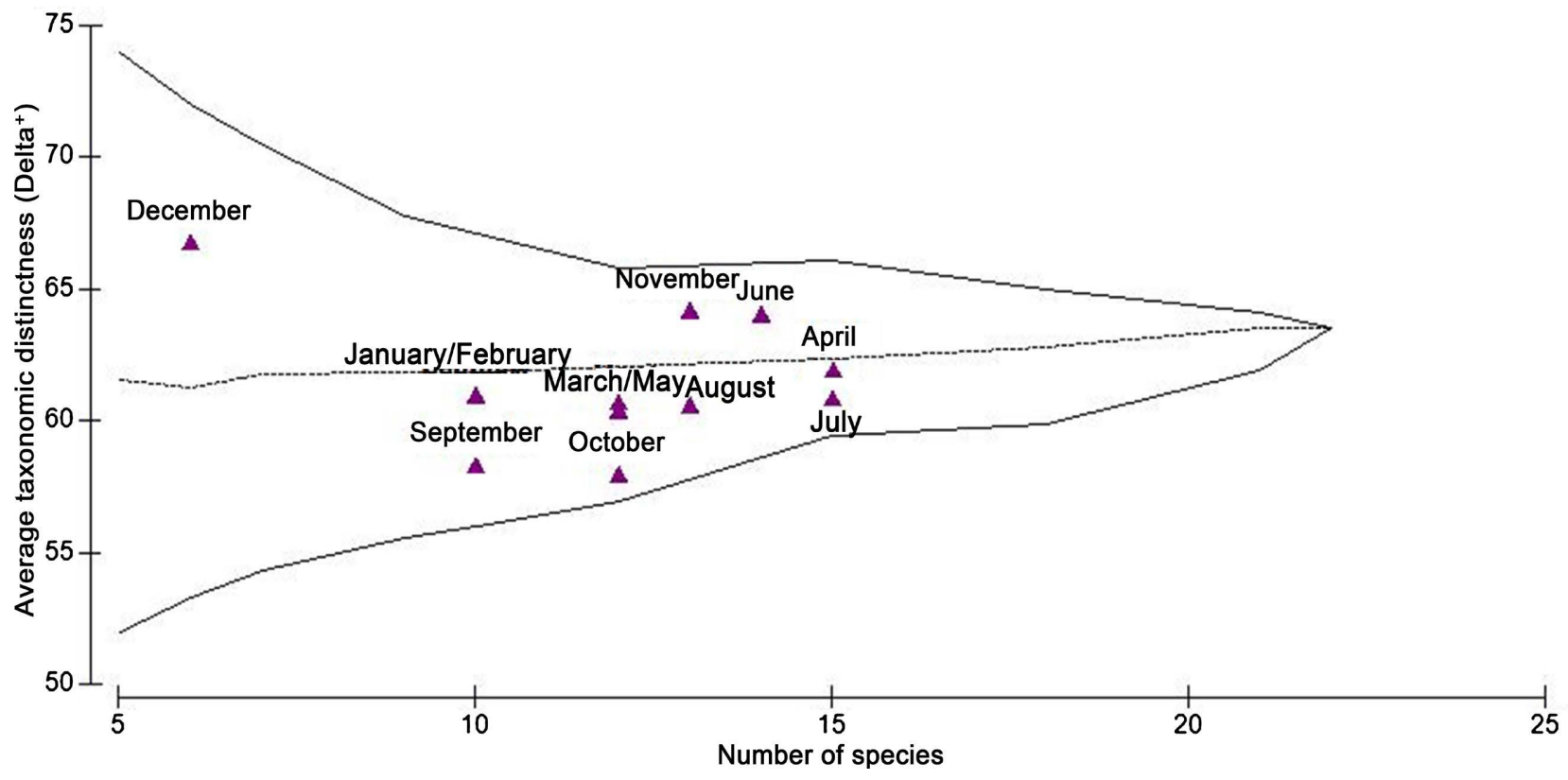

Figure 4. Average taxonomic distinctness $\left(\operatorname{AvTD} \Delta^{+}\right)$at each month. 


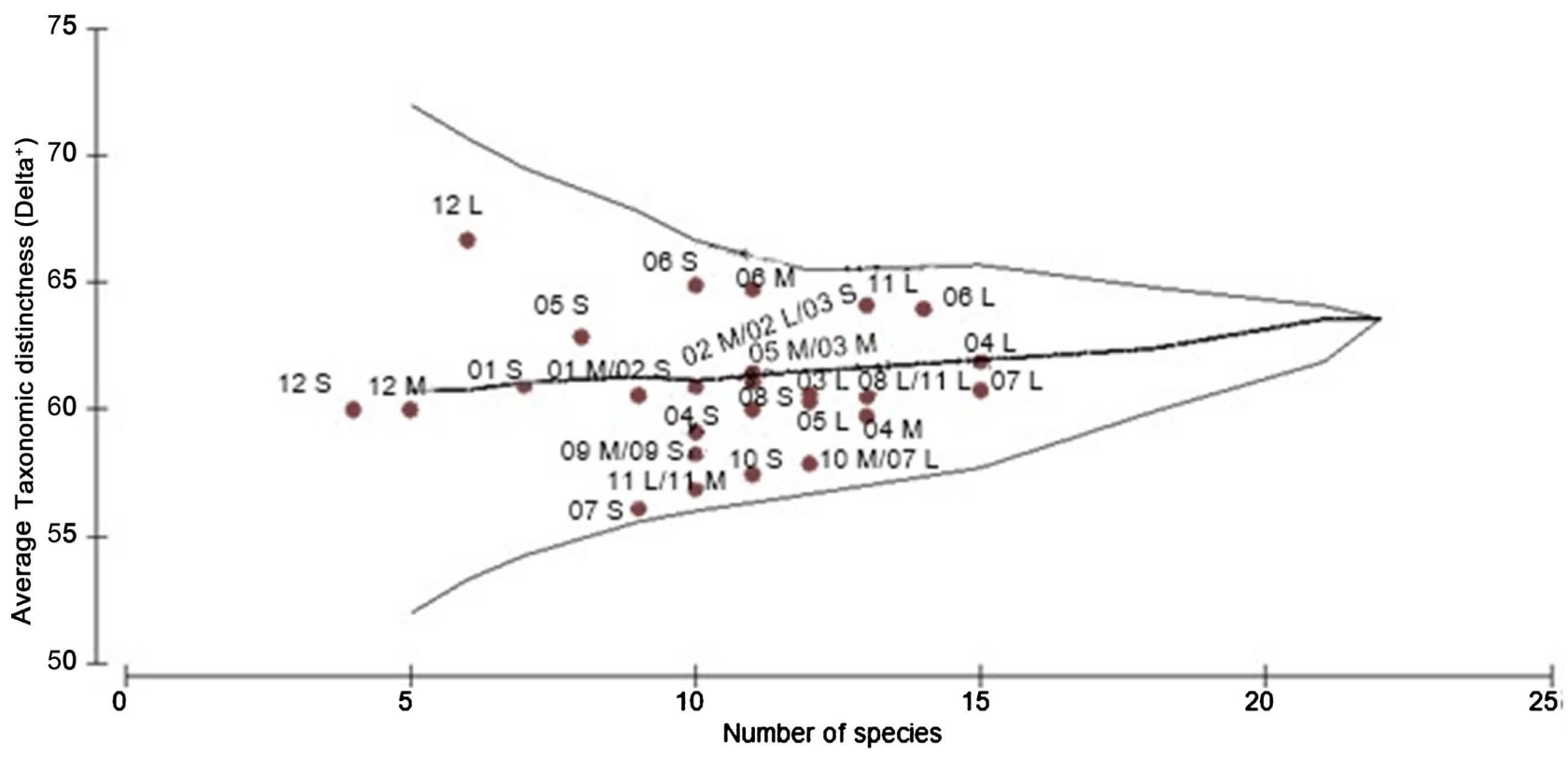

Figure 5. Average taxonomic distinctness $\left(\operatorname{AvTD} \Delta^{+}\right)$of tide pools.

\section{Discussion}

The intertidal zone is highly variable through time and space [12] [13] partly due to seasonal and daily variations of tide and solar radiation [14] [15]. Our study area is characterized by a mixed tidal cycle, which is the reason why physicochemical variables were measured during the afternoon low tide (between 13:30 and 17:30 hr.), and the exposed time of pools during low tide was $6 \mathrm{~h} 20 \mathrm{~min}$. From the three environmental variables measured in our study, temperature showed marked variations throughout the year (Table 1), consistent with previous studies from Chile and El Salvador [3] [16]. Thermal difference between open ocean and tide pools was $4.6^{\circ} \mathrm{C}$ and maximum temperature $\left(32.65^{\circ} \mathrm{C}\right)$ was recorded in September. According to a previous study from El Salvador, as the water gets warmer, fish increase their metabolic activity, and considering an increase of frequency and intensity of warming events due to climate change, fish and other organisms may be challenge, particularly because their survival, growth and reproduction rely on critical temperature ranges. Tide pools in our study area are located $122 \mathrm{~cm}$ above sea level (lowest tide). According to a study from Brazil [17], isolation of the water that is left trapped in tide pools during low tide, alongside evaporation, are important factors that determine composition and distribution of intertidal fish, given the expected variation of temperature throughout the day, particularly during summertime. These authors selected tide pools according to their position above the lowest tide (low, medium, high), and used larger and deeper tide pools, obtaining different temperature, salinity and dissolved oxygen values compared to our own. These differences in environmental variables are probably due to geographic location, because our study site is located in a subtropical region, where fish with temperate and tropical affinities are distributed, and where the variation of environmental factors is 
greater.

Salinity showed variability throughout the year, probably due to evaporation of the water in the tide pools, which can be higher, particularly during the warmer months. These variations are similar to previous studies [3] [16].

Dissolved oxygen increases during the day (due to photosynthesis) and decreases at night (due to a lack of photosynthesis alongside respiration) [18]. According to our results, dissolved oxygen showed significant differences between months, ranging from 5.5 to $25 \mathrm{mg} / \mathrm{L}$. These variations are probably due to a difference in oxygen demand, because of the presence of different organisms molluscs (gastropods, polyplacophora, cephalopods), crustaceans, annelids, sipunculids, anemones, sea urchins and limpets; as well as brown, red and green algae. Abundance of these organisms fluctuates throughout the year, causing a variation of oxygen demand, and probably of dissolved oxygen throughout the duration of our study, similar to previous reports from Cadiz, Spain [18].

When comparing tide pools of different sizes, there were no significant differences of temperature, salinity and dissolved oxygen, suggesting there is no preference on size from fish because environmental conditions are similar in all tide pools, and therefore they are all probably being used as shelters during low tide.

Studies about taxonomic diversity of the intertidal fish community of tropical and subtropical areas in México and other regions are limited [3]. The present study is the first one of its kind using taxonomic distinctness indices linked to environmental variables in this region, therefore becoming an important contribution to the understanding of temporal changes of the structure of the intertidal fish community of the West coast of the Baja California peninsula [4] [5] [19].

Species richness describes changes in the number of species according to sample size [20]. Environmental variables and time fluctuations have a significant impact on the number of species, and therefore, on the species richness. According to our results, overall species richness was 2.80. Previous studies found no significant difference on species richness between tide pools of different sizes, but did found changes between different water volumes [3]. Fish community structure in tide pools is regulated by resources availability such as shelter, food, and others [17]. Considering these factors within our study area, species richness can change throughout the year (Table 1).

Fisher's alpha diversity index [21] evaluates diversity more efficiently considering number of organisms and number of species [22]. Although it is not commonly used, from an ecological perspective, it is well fitted because it does not rely on sample size and all species have the same weight [7] [23] [24]. According to our results, this index showed significant differences when comparing between months $\mathrm{F}(11,24)=2.8299, \mathrm{p}=0.0152$ and between tide pools of different sizes $(\mathrm{F}(2,33)=$ $3.3088, \mathrm{p}=0.0352$ ). Since no previous studies have used this index to analyse intertidal fish communities, we infer this index shows a diverse community, considering we recorded from six to 15 species throughout the year (Table 1). This is inference is based on previous studies, that although analysed fish communities from different habitats such as coastal lagoon, La Paz Bay and San Jose Island, recorded 
similar values to our study (from 9 to 25) [25] [26] [27].

Taxonomic distinctness $\left(\Delta^{*}\right)$ is the path length between any two randomly chosen individuals that are from different species [7]. This index was established to infer if an ecosystem has been subject of anthropogenic impact or is in pristine conditions. Values are adjusted depending on the number of hierarchy levels used; five levels were used for the present study. The use of this type of ecological indices in Mexico is relatively recent. For example, a temporal $\Delta^{*}$ from 49.95 to 229.37 units was reported in San Ignacio lagoon [25]. Another study carried out in San Jose Island reported values from 80 to 153.58 units [27]. Similar values were reported for La Paz Bay [27]. In the present study, we recorded monthly values that range from 50.17 to 186.8 units (Figure 2, Table 1). These differences, compared to those studies, are probably due to a different sampling method like a trawling net, used in San Ignacio lagoon [28]. Our results are similar to those previously reported, even though were carried out in different habitats. When presence/absence data are considered for analysis, taxonomic diversity $(\Delta)$ and taxonomic distinctness $\left(\Delta^{*}\right)$ converge in the same index, average taxonomic distinctness $\left(\Delta^{+}\right)$, which is the length of taxonomic relatedness between two random species [29]. Our results, like those previously reported in San Ignacio [25] [28], San José island [27], and La Paz Bay [25] [30] with values close to the mean, and in some cases, close to the confidence intervals, suggest that our study site is in good ecological condition. There are no previous studies that used these indices (particularly $\Delta^{*}$ and $\Delta^{+}$) to analyse the structure of the intertidal fish community in México or any other region. Therefore, we consider the present study a very important contribution to the knowledge of taxonomic distinctness in fish communities inhabiting intertidal pools, a vulnerable and exposed area to the constant change of critical environmental variables accordingly.

\section{Conclusion}

Physicochemical variables measured in this study showed significant temporal variation. However, considering size and depth of tide pools, there were no significant differences, which suggest that since all tide pools have similar environmental conditions, there are no size preferences and all tide pools are probably being used as shelters during low tide. Temperature is an important environmental variable to include in taxonomic diversity and community structure studies, since it has an impact on biological processes of many organisms, including fish; therefore, given the increase of intensity and frequency of extreme events associated with climate change, particularly global warming, it is important to study the effect of variation of temperature through time, especially during the summer months, in vulnerable ecosystems such as the intertidal zone.

\section{Acknowledgements}

Authors would like to acknowledge UABCS for the use of its facilities (Laborato- 
rio de Ecología de Peces). Dr. Juan Ángel Armenta Q. for georeferencing sampling site. MSc Myrna Barjau Pérez Milicua for the English editing of the manuscript.

\section{Authors' Contributions}

EBG designed and carried out fish collection, analyzed data and wrote the manuscript, JMLV did the figures, JAAQ participated in the visual census surveys, ERV revised the manuscript. All authors read and approved the final manuscript. Likewise, they declare no conflict of interest.

\section{Conflicts of Interest}

The authors declare no conflicts of interest regarding the publication of this paper.

\section{References}

[1] Yanez-Arancibia, A. (2005) Middle America, Coastal Ecology and Geomorphology. In: Schwartz, M.L., Ed., The Encyclopedia of Coastal Sciences, Springer, Dordrecht, 639-645.

[2] Yanez-Arancibia, A., Ramirez-Gordillo, J.J., Day, J.W. and Yos-kowitz, D. (2009) Environmental Sustainability of Economic Trends in the Gulf of Mexico: What Is the Limit for Mexican Coastal Development? In: Cato, J., Ed., Ocean and Coastal Economy of the Gulf of Mexico, Harte Research Institute for Gulf of Mexico Studies. Texas A \& M University Press, College Station, 82-104.

[3] González-Murcia, S.F., Batres, C. and Lovo, M.H. (2016) Community Structure and Height Distribution of Intertidal Rockpool Fish in Los Cóbanos, El Salvador. Pan-American Journal of Aquatic Sciences, 11, 227-242.

[4] Ruiz-Campos, G. and Hammann, M.G. (1987) A Species List of the Rocky Intertidal Fishes of Todos Santos Bay, Baja California, Mexico. Ciencias Marinas, 13, 61-69. https://doi.org/10.7773/cm.v13i1.524

[5] Ruiz-Campos, G., González-Guzmán, S., Ramírez-Valdez, A., Gonzalez-Acosta, A.F., Castro-Aguirre, L.J. and Cruz-Agüero, J.D. (2010) Composition, Density and Biogeographic Affinities of the Rocky Intertidal Fishes on the Western Coast of the Baja California península, Mexico. California Cooperative Oceanic Fisheries Investigations, Vol. 51, 210-220.

[6] Clarke, K.R. and Warwick, R.M. (1999) The Taxonomic Distinctness Measure of Biodiversity: Weighting of Step Lengths between Hierarchical Levels. Marine Ecology Progress Series, 184, 21-29. https://doi.org/10.3354/meps184021

[7] Clarke, K.R. and Warwik, R.M. (2001) A Further Biodiversity Index Applicable to Species List: Variations in Taxconomic Distinctness. Marine Ecology Progress Series, 216, 265-278.

[8] Miller, D.J. and Lea, R.N. (1972) Guide to the Coastal Marine Fiches of California. California Fish Bulletin Number 157, UCANR Publications, 235 p.

[9] Zahuranec, B.V. (1967) The Gerreid Fishes of the Genus Eucinostomus in the Eastern Pacific. Tesis Maestría en Ciencias, Scripps Institution of Ocenography, University of California, La Jolla, San Diego, 74 p.

[10] Allen, G.R. and Ross-Robertson, D. (1998) Peces del Pacífico Oriental Tropical. 
Crawford House Press Pty Ltd., 2da. Edición en español, CANABIO y Agrupación Sierra Madre, S.C. 327 p.

[11] Fisher, W., Krupp, F., Schneider, W., Sommer, C., Carpenter, K.E. and Niem, V.H. (1995) Guía FAO para la identificación de especies para los fines de pesca. Pacífico centro-oriental. FAO, Roma, Vol. II, III, 647-1813.

[12] Briggs, J.C. (1974) Marine Zoogeography. McGraw-Hill Book Company, New York, $475 \mathrm{p}$.

[13] Little, C. and KitChing, J.A. (1996) The Biology of Rocky Shores. Oxford University Press, Oxford, $252 \mathrm{p}$.

[14] Metaxas, A. and Scheibling, R.E. (1993) Community Structure and Organization of Tidepools. Marine Ecology Progress Series, 98, 187-198. https://doi.org/10.3354/meps098187

[15] Metaxas, A. and Scheibling, R.E. (1994) Spatial and Temporal Variability of Tidepool Hyperbenthos on a Rocky Shore in Nova Scotia, Canada. Marine Ecology Progress Series, 108, 175-184. https://doi.org/10.3354/meps108175

[16] Hernández, C.E., Neill, P.E., Pulgar, J.M., Ojeda, F.P. and Bozinovic, F. (2002) Water Temperature Fluctuations and Territoriality in the Intertidal Zone: Two Possible Explanations for the Elevational Distribution of Body Size in Graus nigra. Journal of Fish Biology, 61, 472-488. https://doi.org/10.1111/j.1095-8649.2002.tb01578.x

[17] White, G.E., Hose, G.C. and Brown, C. (2015) Influence of Rock-Pool Characteristics on the Distribution and Abundance of Intertidal Fishes. Marine Ecology, 36, 1332-1344.

[18] Velazco, G. (2006) Ictiofauna intermareal de una plataforma rocosa del Golfo de Cádiz: Ciclos de vida, utilización del espacio y relaciones tróficas. Tesis doctoral, Universidad de Cádiz.

[19] Barjau-Gonzalez, E., Romo-Pineda, A.K., Lopez-Vivas, J.M., Perez-Castillo, J. and Barjau-Perez Milicua, M. (2017) Variation of the Structure of the Intertidal Fish Community of the Pacific Coast of Baja California Sur, Mexico. International Journal of Marine Science, 7, 455-461.

[20] Margalef, D.R. (1969) Perspective in Ecological Theory. Chicago University, Chicago.

[21] Fisher, R., Corbet, S. and Williams, C. (1943) The Relation between the Number of Species and the Number of Individual in a Random Sample of an Animal Population. Journal of Animal Ecology, 12, 42-58. https://doi.org/10.2307/1411

[22] Condit, R., Hubbell, S.P. and Foster, R.B. (1996) Changes in Tree Species Abundance in a Neotropical Forest: Impact of Climate Change. Journal of Tropical Ecology, 12, 231-256. https://doi.org/10.1017/S0266467400009433

[23] Magurran, A.E. (2004) Measuring Biological Diversity. Blackwell Publishing, Oxford, $256 \mathrm{p}$.

[24] Moreno, C.E. (2001) 23, Métodos para medir la biodiversidad. M\&T-Manuales y tesis SEA, Vol. I, Zaragoza, España 84 p.

[25] Barjau-Gonzalez, E., Rodriguez-Romero, J. and Galvan-Magana, F. (2014) Diversidad taxonomica del ensamblaje de peces arrecifales en la costa oeste de la bahia de La Paz, BCS, Mexico. Revista Cientifica Biologico Agropecuaria Tuxpan, 2, 117-125.

[26] Barjau-Gonzalez, E., Rodriguez-Romero, J., Galvan-Magana, F. and Maldonado-Garcia, M. (2016) Seasonal Shift in the Taxonomic Diversity of Rocky Reef Fishes in the Southwestern Gulf of California. Revista de Biologia Marina $y$ Oceanografia, 51, 11-19. https://doi.org/10.4067/S0718-19572016000100002 
[27] Barjau-Gonzalez, E. (2012) Estructura comunitaria y diversidad taxonomica de los peces en la bahia de La Paz y la isla San Jose, Golfo de California. Tesis de Doctorado, CIBNOR, $149 \mathrm{p}$.

[28] Juaristi-Videgaray, D., Barjau-Gonzalez, E., Vadillo-Romero, E. and Romo-Pinera, A.K. (2014) Variation in Taxonomic Diversity of the Fish Assemblage Associated with Soft Bottoms in San Ignacio Lagoon, Baja California Sur, Mexico. Journal of Biodiversity, Bioprospecting and Development, 1, 1-8.

[29] Perez-Castillo, J., Barjau-Gonzalez, E., Lopez-Vivas, J.M. and Armenta-Quintana, J.A. (2018) Taxonomic Diversity of the Fish Community Associated with Soft Bottoms in a Coastal Lagoon of the West Coast of Baja California Sur, Mexico. International Journal of Marine Science, 9, 20-29.

[30] Sohier, C. (2008) Measurements of Biodiversity.

http://www.coastalwiki.org/wiki/Measurements of biodiversity 